\title{
Metrizamide CT Scanning in Spinal Nerve Root Cysts
}

\author{
R.N. Goyal, N.A. Russell, J.M.E.G. Belanger, B.G. Benoit and M. Rawa
}

\begin{abstract}
Two cases of lumbosacral root cysts of different etiology are reported. Their specific radiographic features are described using the combined technique of metrizamide myelography followed by computerized tomography of the spine. The terminology of intraspinal cysts is reviewed and their distinguishing features discussed.

RÉSUMÉ: Tomodensitométrie à la métrizamide en recherchant les kystes dans les racines spinales. Nous rapportons deux cas de kystes dans les racines spinales provenant de différentes étiologies. Les caractéristiques radiographiques particulières ont été étudiées employant la technique de myélographie à la métrizamide, suivie par la tomodensitométrie de l'épine. Nous discutons la terminologie des kystes intraspinaux ainsi que leurs traits reconnaissables.
\end{abstract}

Can. J. Neurol. Sci. 1987; 14:149-152

Early studies of nerve root cysts relied upon plain radiographs for diagnosis, by demonstrating the associated bony erosions. ${ }^{1.2 .3}$ Direct visualization of these cysts became possible with the introduction of contrast myelography, $4,5,6,7,8$ although the original oil based agents had certain limitations. They are viscous, a property which prevents their free flow into the cysts. Unless there is a widely patent communication with the spinal subarachnoid space, this type of myelography will display the cysts only as negative filling defects. Eventually the contrast may seep through even a narrow communication, so that delayed screenings will demonstrate the cysts directly. ${ }^{9}$ With computerized tomography (CT) there is a better appreciation of nerve root anatomy, ${ }^{10,11,12-14}$ although the intraarachnoidal structures are poorly imaged. ${ }^{15}$ However, when myelography using the water soluble contrast agent metrizamide is combined with CT scanning of the spine, a precise display of the whole nerve root and its intra-arachnoidal components is achieved. ${ }^{16,17}$ Further improvements in diagnosis may occur as the technique of magnetic resonance imaging (MRI) evolves. ${ }^{18}$

These advances have led to the recognition of a variety of abnormalities of spinal nerve roots. Since the different characteristics of various nerve root cysts are not always appreciated, the terminology has become confused. Because of Tarlov's original work, ' many are incorrectly called perineural cysts and different terms are often used to describe the same lesion. ${ }^{15} \mathrm{We}$ report two cases which illustrate this point and discuss the efficacy of metrizamide myelography combined with CT in the investigation of spinal nerve root cysts.

\section{CASE REPORTS}

\section{Patient 1}

A 51-year-old man was admitted to hospital in 1982 for investigation of low back and right leg pain. The back pain was located in his lumbosacral region and had been present for approximately 10 years. It was aggravated by exertion and partially relieved by rest. Three years prior to admission he developed right leg pain, radiating from his buttock to his foot in the distribution of the L5 dermatome. He had had accidents in 1951 and in 1968, resulting in fractures of his pelvis, right hip and right femoral shaft.

Examination revealed no abnormality of his spine. Right sided straight leg raising elicited mild low back pain at 80 degrees. There was no neurological abnormality. Plain radiographs of the lumbosacral spine showed erosion of the right pedicle of L5 (Figure 1). Computerized tomographic scanning demonstrated an isodense cystic lesion in the right L5 neural foramen, associated with the pedicle erosion (Figure 2). Metrizamide myelogram confirmed the presence of a solitary cyst located on the right L5 nerve root (Figure 3). A right L4/5 laminectomy was performed. The disc at this level appeared normal. The fifth lumbar root was traced laterally to the pedicle. There was a cystic dilatation of the root sleeve beginning at a point opposite the root axilla and extending distally approximately $1 \mathrm{~cm}$. It was relatively diffuse with no obvious neck. Its wall seemed to consist of thinned dura. Treatment consisted of simple bony decompression. In the immediate postoperative period he was relieved of pain and at follow-up six months later was still pain free. We believe that the lesion was a post-traumatic nerve root cyst.

\section{Patient 2}

A 58-year-old woman presented with a four year history of low back pain, which had increased in severity during the preceeding six months. It radiated into her left buttock and down the posterior aspect of her left leg to the mid-calf. It was aggravated by straining, prolonged standing and walking. There were no other symptoms. Her past medical history 
was unremarkable. Physical examination revealed a normal stance and gait. Spinal motion was normal. Left sided straight leg raising produced low back pain at 45 degrees. There was no neurological abnormality.

Nerve conduction studies showed light prolongation of the H-reflex in each leg, suggesting bilateral SI radiculopathies. Plain radiographs of the lumbar spine showed scalloping of the posterior surfaces of the bodies of L5 and S1 (Figure 4a). Metrizamide myelography demonstrated multiple nerve root cysts that were associated with the bony changes (Figure 4b). CT scanning after intrathecal metrizamide clearly displayed the configuration of the cysts and their association with the widened neural foramina (Figure 5a). Within the cysts were fluid levels composed of CSF and contrast material. The contrast was dependent because of its greater density (Figure $5 b$ ). The cysts were bilateral and located on the spinal roots from L3 through S1 (Figure 6). They were proximal to the dorsal root ganglion and were easily filled by contrast material. We believe them to represent the saccular variety of nerve root sleeve dilatation. ${ }^{15}$ Surgical treatment was discussed but the patient declined to consider it.

\section{Discussion}

Lumbosacral nerve root cysts are relatively common, ${ }^{16}$ an incidence of 17 percent being reported in patients undergoing

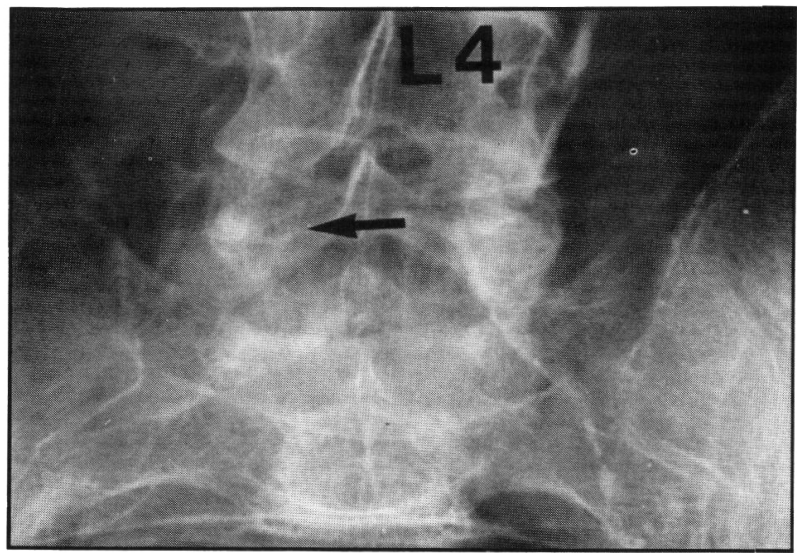

Figure 1 - Plain $x$-ray of lumbosacral spine in anteroposterior view. Note the pedicle erosion of right $L 5$ (arrow).

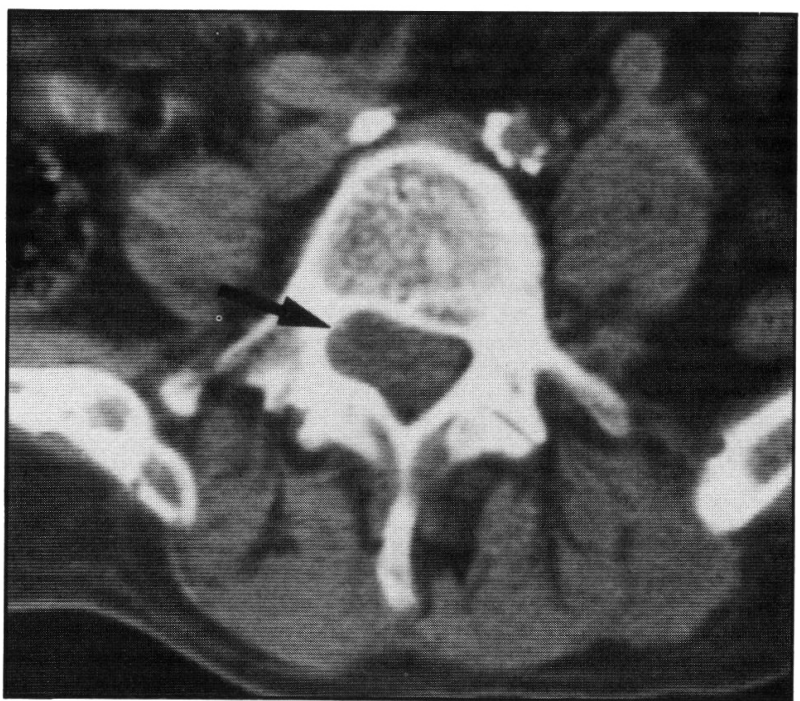

Figure $2-C T$ scan prior to metrizamide myelography. Note the isodense rounded cyst situated in the neural foramen on the right, associated with smooth erosion of the medial aspect of the pedicle and the dorsolateral aspect of the vertebral body (arrow). myelography for the investigation of low back pain and sciatica. ${ }^{19}$ There are four broad categories which include perineural cysts, ${ }^{1}$ root sleeve dilatations, ${ }^{7.19}$ arachnoid cysts ${ }^{20.21 .22}$ and traumatic root cysts. ${ }^{28}$

The meninges and subarachnoid space enclose the nerve root laterally, as far as the dorsal root ganglion and end by merging with the perineurium. ${ }^{23}$ This forms the root sleeve or sheath. Tarlov ${ }^{1}$ believed that perineural cysts arose following traumatic hemorrhage leading to splitting of the nerve root sheath. Subsequent distension of the potential space between the endoneurium and perineurium resulted in cyst formation. It is usually located at, or just distal to, the dorsal root ganglion on the sacral and coccygeal roots. It does not communicate freely with the spinal subarachnoid space. Unlike other cystic lesions, part of its lining contains neural tissue. When these criteria were strictly applied, Nishiura ${ }^{17}$ could find only 16 cases of true perineural cysts in the literature.

Root sleeve dilatation ${ }^{19}$ may originate in degenerative change or congenital weakness of the meningeal covering of the root. This results in dilatation of the subarachnoid space up to the site where the dura and arachnoid fuse with the perineurium. A diffuse dilatation is called "tubular" whereas one localized to the distal part of the sheath is called "saccular". ${ }^{15}$ Strully" described an entity called meningeal diverticulum. This seems identical to the "saccular" variety of root sleeve dilatation. Neave and $\mathrm{Wycoff}^{15}$ have summarized the myelographic features of this lesion. These include free passage of the contrast material between the subarachnoid space and the dilated root

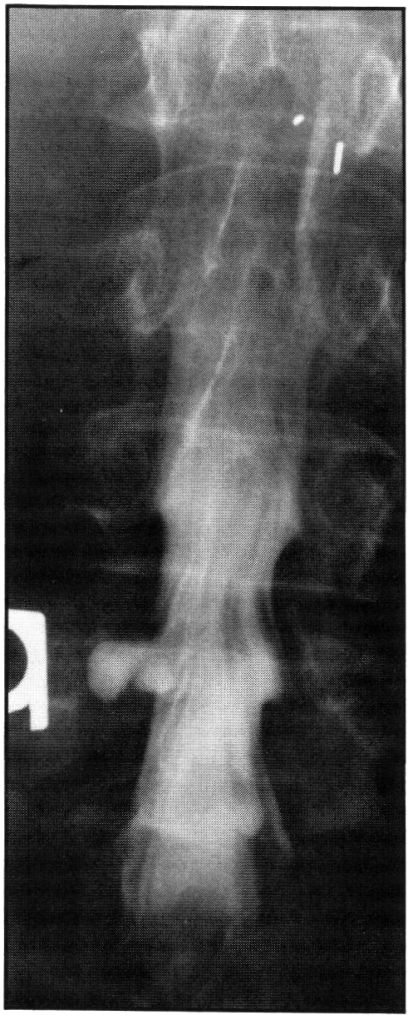

Figure 3 - Metrizamide myelogram showing a solitary cyst at the 25 root on the right side. 
sleeve, multiple bilaterally symmetrical lesions in more than 50 percent of patients, involvement mainly of the sacral roots, a cephalo-caudad accentuation, and occasionally an enlargement of the whole dural sac.

The extradural arachnoid cyst arises from an evagination of arachnoid through a congenital dural defect and thus lacks a dural covering. It is termed an arachnoid diverticulum ${ }^{15}$ if its communication with the subarachnoid space remains patent. If this becomes obliterated then the term arachnoid cyst is more appropriate. ${ }^{21}$ It may also be intradural, where it is believed to arise from a congenital splitting or duplication of the arachnoid, ${ }^{24}$ in which cerebrospinal fluid loculates.

Trauma to the dura during surgery may lead to an arachnoid diverticulum. If the injury involves the arachnoid also, cerebrospinal fluid may leak into the surrounding tissues to form a pseudocyst. ${ }^{25}$ These iatrogenic cysts should be differentiated from those that arise after root avulsion or root sleeve tear due to closed spinal injury. ${ }^{26.27 .28}$ In the latter, the arachnoid is

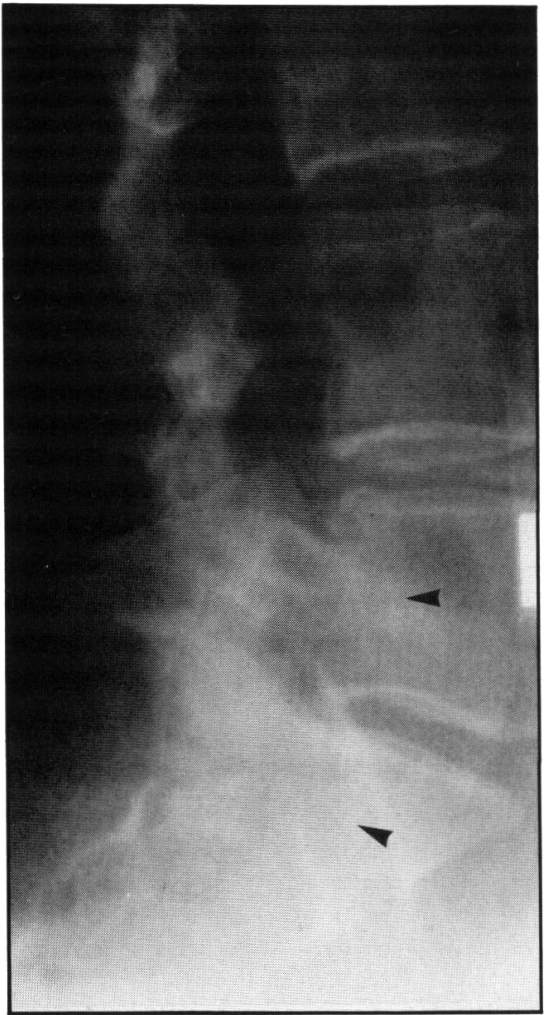

$\mathbf{A}$

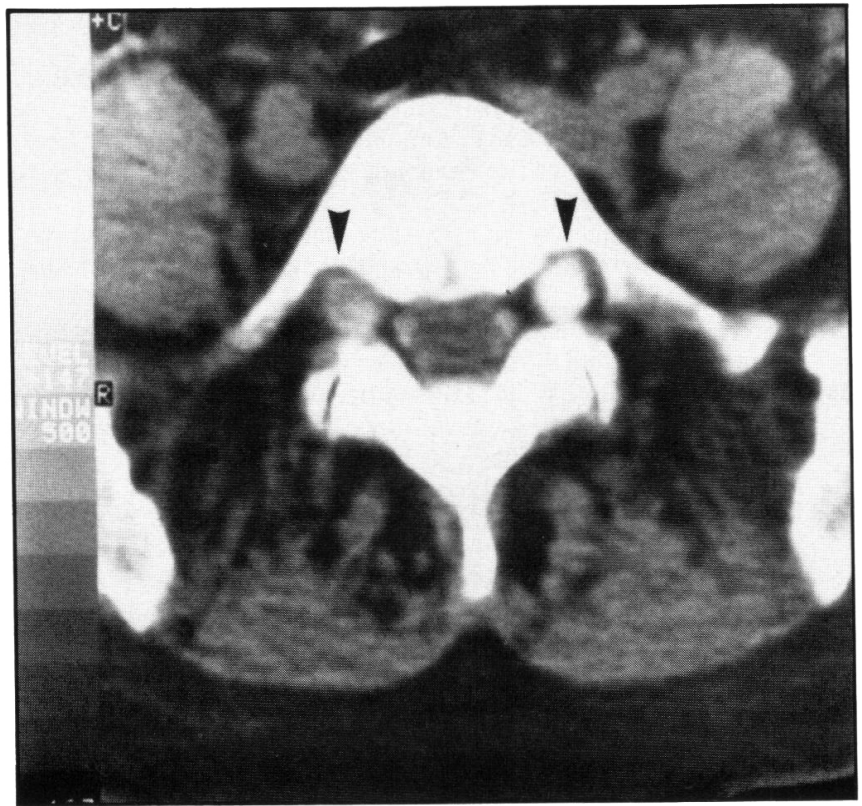

Figure $5 a-C T$ scan examination with intrathecal metrizamide shows widening of neural foramina by the cysts (arrows).

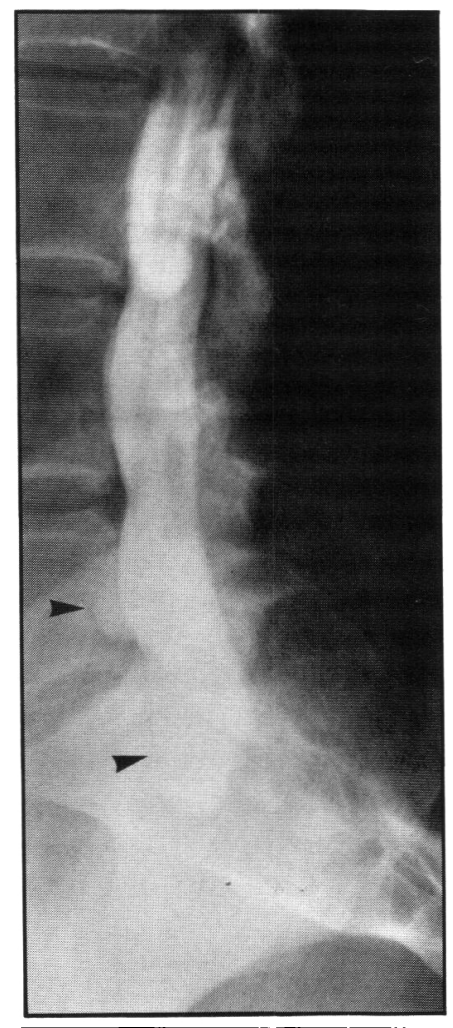

Figure $4 a-$ Plain $x$-rays of lumbosacral spine. Note the scalloped erosions of the posterior aspects of the bodies of $L 5$ and SI (arrow's).

Figure $4 b-$ Metrizamide myelogram. Contrast material fills the cyst demonstrating their association with the vertebral erosions (arrows). 
torn but the dural component of the root sleeve remains intact. When exposed directly to the pulsatile pressure of cerebrospinal fluid the dura undergoes cystic dilatation. This is traditionally called traumatic root cyst and usually involves the fifth lumbar root.

To our knowledge, the use of metrizamide myelography combined with $\mathrm{CT}$ scanning in the investigation of spinal nerve root cysts has been described only once previously. ${ }^{17}$ Three other papers report using the two procedures separately. 13.14.15 In these cases CT without metrizamide enhancement, clearly displayed the localized bony erosions associated with the cysts. Attenuation values isodense with water suggested the cystic nature of the eroding masses. ${ }^{14.15}$ This feature is not specific for a nerve root cyst since a degenerating neurofibroma could show similar values. ${ }^{14}$ Metrizamide myelography subsequently confirmed the diagnosis of spinal nerve root cysts.

Many authors have associated a syndrome of low back pain, sciatica, and occasional focal neurological abnormalities with spinal nerve root cysts. ${ }^{1.4 .7 .9 .29-31}$ Although there is no consensus, surgery is usually recommended if the cyst exhibits mass effect and particularly if the symptoms can be localized to a particular root. The precise diagnosis afforded by combining metrizamide myelography with CT improves the likelihood of choosing appropriate treatment. This technique will confirm the cystic nature of a nerve root lesion, display its spatial relationship and any communication with the spinal subarachnoid space. It will also demonstrate the size and reveal any evidence of nerve root displacement. ${ }^{17}$

\section{ACKNOWLEDGEMENT}

The authors wish to acknowledge the painstaking efforts of Donna Headrick for typing the repeated revisions of the manuscript.

\section{REFERENCES}

1. Tarlov IM. Perineurial cysts of the spinal nerve roots. Arch Neurol Psychiat (Chic) 1938; 40: 1067-1074.

2. Weiford EC. Sacral perineurial cysts with case report. Cleveland Clin Quart 1950; 17: 106-111.

3. Hadley LA. The value of routine plain roentgenograms in the diagnosis of sacral perineurial cysts. Amer J Roentgenol 1960;84: $119-124$

4. Schreiber F, Haddad B. Lumbar and sacral cysts causing pain. J Neurosurg 1951; 8: 504-509.

5. Taheri ZE, Riemenschneider P, and Ecker A. Myelographic diagnosis of sacral perineural cyst. J. Neurosurg 1952; 9: 93-95.

6. Jacobs LG, Smith JK and Van Horn PS. Myelographic demonstration of cysts of spinal membranes. Radiology 1954: 62: 215-221.

7. Strully KJ. Meningeal diverticuli of sacral nerve roots (perineurial cysts). J Amer Med Ass 1956; 161: 1147-1152.

8. Seaman WB, Furlow LT. The myelographic appearance of sacral cysts. J Neurosurg 1956; 13: 88-94.

9. Tarlov IM. Spinal perineural and meningeal cysts. J Neurol Neurosurg Psychiat 1970; 33: 833-843.

10. Naidich TP, King DG, Moran CJ, et al. Computed tomography of the lumbar thecal sac. J Comput Assist Tomgr 1980; 4: 37-41.

11. Raskin SP. Demonstration of nerve roots on unenhanced computed tomographic scans. J Comput Assist Tomogr 1981; 5: 281-294.

12. Batnitsky S, Soye I, Levine E, et al. CT in the evaluation of lesions arising in and around the sacrum. Radiographics 1982;2:506.

13. Siqueira EB, Schaffer L, Kranzler LI, et al. CT characteristics of sacral perineural cysts. Report of two cases. J Neurosurg 1984; 61: $596-598$

14. Willinsky RA, Fazl M. Case report: computed tomography of a sacral perineural cyst. J Comput Assist Tomogr 1985;9: 599-601.

15. Neave VCD, Wycoff RR. Computed tomography of cystic nerve root sleeve dilatation. J Comput Assist Tomogr 1983: 7: 881-885.

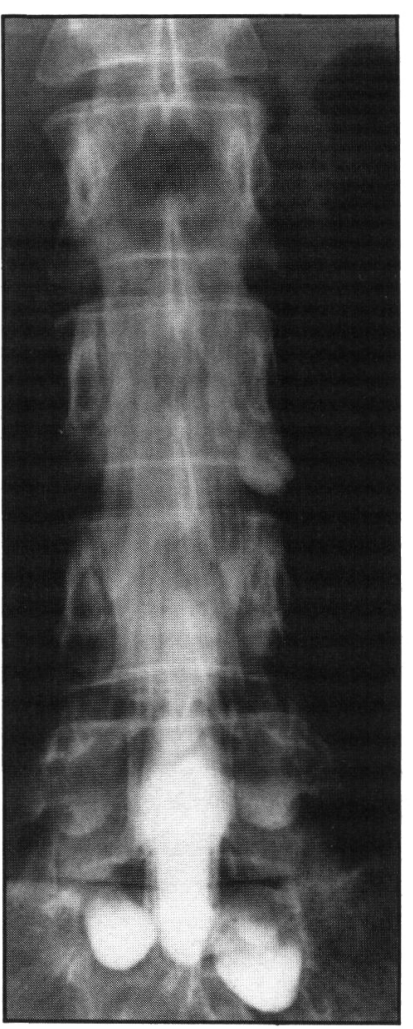

Figure 6-Metrizamide myelogram $A P$ view. Note the bilateral root sleeve dilatations from $\mathrm{L} 3$ through $S I$.
16. Capesius P, Babin E. Radiculosaccography with water soluble contrast media. New York: Springer-Verlag 1978: 101-106.

17. Nishiura I, Koyama $T$ and Handa J. Intrasacral perineural cyst. Surg Neurol 1985; 23: 265-269.

18. Rodziewicz GS, Kaufman B, Spetzler RF. Diagnosis of sacral perineural cysts by nuclear magnetic resonance. Surg Neurol 1984; $22: 50-52$.

19. Larsen JL, Smith D, Fossan G. Arachnoidal diverticula and cyst like dilatations of the nerve root sheaths in lumbar myelography. Acta Radio (Stockh) 1980; 21: 141-145.

20. Raja IA, Hankinson J. Congenital spinal arachnoid cyst. Report of two cases and review of literature. J Neurol Neurosurg Psychiat 1970; 33: 105-110.

21. McCrum C, Williams B. Spinal extradural arachnoid pouches. J Neurosurg 1982; 57: 849-852.

22. DiSclafani A, Canale DJ. Communicating spinal arachnoid cyst. Diagnosis by delayed metrizamide computed tomography. Surg Neurol 1985; 23: 428-430.

23. Rexed BA, Wernstrom KG. Arachnoidal proliferation and cystic formation in the spinal nerve root pouches of man. J Neurosurg 1959; 16: 73-84.

24. Perret G, Green D, Keller J. Diagnosis and treatment of intradural arachnoid cysts of the thoracic spine. Radiology 1962;79:425-429.

25. Miller PR, Elder FW jr. Meningeal pseudocysts (meningocele spurious) following laminectomy. J Bone Jt Surg 1968; 50A: 268-276.

26. Lyons WR, Woodhall B. Atlas of peripheral nerve injuries. London: W B Saunders publishers 1949.

27. White JC, Hanelin J. Myelographic sign of brachial plexus avulsion. J Bone Jt Surg 1954; 36A: 113-118.

28. Mclennan JE, McLaughlin WT, Skillicorn SA. Traumatic lumbar nerve root meningocele. J Neurosurg 1973; 39: 528-532.

29. Schur PH. Sacral extradural cyst an uncommon cause of low back pain. J Bone Jt Surg 1955; 37B: 601-605.

30. Abbott KH, Retter RH, Leimbach WH. The role of perineurial sacral cysts in the sciatic and sacrococcygeal syndromes. A review of literature and report of 9 cases. J Neurosurg 1957; 145: 5-21.

31. Teng P, Rudner N. Multiple arachnoid diverticula. Arch Neurol (Chic) $1960 ; 2: 348-356$. 